\title{
Cardiovascular Drugs and Therapy Celebrates its 30th Year with the Appointment of a New Co-Editor-in-Chief
}

\author{
Willem J. Remme ${ }^{1}$
}

Published online: 30 March 2016

(C) Springer Science+Business Media New York 2016

This year it will be 30 years ago that Cardiovascular Drugs and Therapy, commonly known by its abbreviated title CDT, was founded by Henry Neufeld and Lionel Opie. Whereas, unfortunately, Henry Neufeld died before the first issue was published, Lionel Opie continued as Editor-in-Chief for the first 15 years of the Journal's existence, and made the journal to flourish together with Elliot Rapaport who served as CoEditor-in-Chief from 1988 to 1998

In 2001 I followed up Lionel Opie as the Journal's Editor-inChief and have been in this fortunate position since that time.

Fortunate as CDT has steadily improved during those years and has obtained citation indices of more than 3 in the last 5 years. The journal is currently well known as indicated by the large yearly number of downloads of up to 60.000. An important aspect of CDT is its fast handling of the manuscripts (for example an average of 19 days from receipt to first decision and 19 days between acceptance and on-line publication [2015 figures]). This achievement is to a large extent the result of the excellent support and hard work of an experienced team of Associate and Section Editors and of members of the Editorial Board.

CDT is designed to cover the bench to bedside development of cardiovascular drug, device and cell therapy and to provide an up-to-date account of relevant research in a broad spectrum of cardiovascular diseases including cardiotoxicity, ischaemic syndromes, cardioprotection, atherosclerosis, hyperlipidemia, diabetes and arrhythmias.

This approach is, by design, extensive and can be very demanding for a sole Editor-in-Chief, certainly when the

Willem J. Remme

w.j.remme@sticaresfoundation.org

1 Cardiovascual Drugs and Therapy, Rotterdam, Netherlands ultimate goal is to keep improving the standard of the Journal and to achieve a continuously increasing citation index.

I am therefore very happy to be able to announce that Dr. Robert S. Rosenson has accepted the position of Co-Editor in Chief of Cardiovascular Drugs and Therapy.

Robert S. Rosenson, MD, is Professor of Medicine at the Icahn School of Medicine at Mount where he serves as Director of Cardiometabolic Disorders. He is a Fellow of the American Heart Association Council on Epidemiology and Prevention, Fellow of the American Heart Association Council on Arteriosclerosis, Thrombosis and Vascular Biology and Fellow of the National Lipid Association

He currently serves on a number of committees for professional societies, including the American College of Cardiology. He has been extensively involved with the National Lipid Association where he serves a National Board Member and Northeast Lipid Association Board Member. Dr. Rosenson served as Co-Chair for the task force on HDL biology, and he served as Chair of the National Lipid Association Statin Safety Expert Muscle Document Committee. Dr. Rosenson led four international working groups on HDL that resulted in seminal articles on HDL nomenclature, HDL and macrophage cholesterol, and HDL functionality.

Dr. Rosenson has been involved in numerous research investigations studying the effects of lipid-lowering therapy, hypoglycemic therapy, and antihypertensive agents in inflammation, thrombogenesis, and rheology. His laboratory was the first to demonstrate that statins reduce pro-inflammatory cytokine production. He has continued this work through mechanistic studies on inflammatory markers with studies on fenofibrate. Most recently, he has conducted research with selective inhibitors of inflammatory pathways such as lipoprotein-associated phospholipase A2, and secretory 
phospholipase A2. He has made important contributions concerning the prognostic significance of lipoprotein subclasses in coronary atherosclerosis, cardiovascular events and prediction of type 2 diabetes. He served as Global Principal Investigator of the PLASMA I, PLASMA II and FRANCIS trials. He has authored more than 260 peerreview journal articles, and 700 book chapters, abstracts, and electronic publications for Up To Date Medicine.

Dr. Rosenson has been extensively involved with Cardiovascular Drugs and Therapy and hence knows the Journal well. He has been for many years an Associate Editor and in that position has been very active and supportive of the Journal and me as its Editor-in-Chief. Dr. Rosenson has designed and edited several successful sections, including a section on Phospholipases, Inflammation and Cardiovascular Disease (volume 23, No 1, 2009) and the Special Issue on Biological Causality: When Experimental Models and Human Genetics Conflict (first issue this year, co-edited with Dr. W. Koenig). In addition, Dr. Rosenson authored 22 articles in Cardiovascular Drugs and Therapy. His recent contribtions include several important publications and critical editorials [1-7]. Moreover, as Associate Editor Dr. Rosenson advised on the choice of reviewers and on acceptance or rejects of submissions to the Journal.

I am convinced that with this experience and his expert knowledge of a broad area of cardiovascular diseases, including atherosclerosis, hyperlipidemia, diabetes and hypertension, Dr. Rosenson is in a unique position to serve as CoEditor-in-Chief of Cardiovascular Drugs and Therapy.
I am delighted therefore that he has accepted his new function and look forward to working with him as Co-Editor-inChief

\section{References}

1. Cho L, Rocco M, Colquhoun D, Sullivan D, Rosenson RS, Dent R, Xue A, Scott R, Wasserman SM, Stroes E. Clinical profile of statin intolerance in the phase 3 GAUSS-2 study. Cardiovasc Drugs Ther. 2016; March 2 [Epub ahead of print].

2. Levitan EB, Muntner P, Chen L, Deng L, Kilgore ML, Becker D, Glasser SP, Safford MM, Howard G, Kilpatrick R, Rosenson RS. Burden of coronary heart disease rehospitalizations following acute myocardial infarction in older adults. Cardiovasc Drugs Ther 2016; Feb. 22 [Epub ahead of print].

3. Rosenson RS, Koenig W. Mendelian randomization analyses for selection of therapeutic targets for cardiovascular disease prevention: a note of circumspection. Cardiovasc Drugs Ther. 2016;30:65-741.

4. Rosenson RS, Brewer Jr HB. New challenges for HDL-modifying therapies as a strategy to lower cardiovascular disease events in statin-treated patients. Cardiovasc Drugs Ther. 2015;29:1-3.

5. Rosenson RS, Davidson MH, Le NA, Burkle J, Pourfarzib R. Underappreciated opportunities for high-density lipoprotein particles in risk stratification and potential targets of therapy. Cardiovasc Drugs Ther. 2015;29:41-50.

6. Rosenson RS, Rigby SP, Jones MR, Chou HS. Effect of colesevelam $\mathrm{HCl}$ monotherapy on lipid particles in type 2 diabetes mellitus. Cardiovasc Drugs Ther. 2014;28:229-36.

7. Myerson M, Rosenson RS. 2013 ACC/AHA Guideline: a guideline for the population - without evidence from the population. Cardiovasc Drugs Ther. 2014;28:203-4. 